The connection between the keratitis and conjunctivitis aestivalis is also considered. The conclusion of the author is, that they are two separate diseases.

The fact that they often are found together, is explained by the fact, that they have a partly common aetiology.

\title{
INTRA-OCULAR TUMOURS
}

BY

\section{William Susman}

FROM THE DEPARTMENT OF PATHOLOGY, MANCHESTER UNIVERSITY, AND THE ROYAL EYE HOSPITAL, MANCHESTER

IN practice, intra-ocular tumours are vaguely classified as gliomata if they originate in the retina, or as melanomata if they have originated in the choroid and contain brown pigment that does not give the iron reaction. Those attempting greater precision place most of the gliomata in the more restricted group of retinoblastomata. The problem, however, is not so simple, for on closer examination a more detailed grouping becomes necessary.

Tumours occurring in other parts of the body have been classified with varying degrees of success, according to the development of the tissue of the part. Similarly, the classification of intra-ocular tumours can be based on retinal and choroidal development. In the present paper a series of 60 intra-ocular tumours is reviewed and a classification is attempted on a developmental basis.

\section{Material}

In the earlier stages the eyes were fixed in 10 per cent. formol saline, frozen with carbon dioxide snow, cut antero-posteriorly through the optic nerve, and then prepared according to the paraffin method. Later Helly's fluid was employed as the fixative, and the eyes were cut after fixation as for the previous method. By this latter procedure the inner portions of the eye did not collapse since the vitreous had coagulated during fixation. The sections were stained with haemalum and eosin, and these stains proved adequate in most cases.

According to some workers all neurological material must be prepared by complicated stains and impregnation methods. However, the haemalum and eosin appearance of the various cells in neural development have been described repeatedly, and although 
the fine details may be lacking, haemalum and eosin staining gives sufficient detail for diagnostic purposes and it is better adapted to routine examinations than the more complicated methods.

\section{Existing Classifications}

Collins and Mayou (1925) group intra-ocular tumours as a whole into the following divisions :-

1. Teleplasms, (a) mesoblastic (choroid),

(1) pigmented,

(2) non-pigmented,

(b) neural epiblastic,

(c) of mixed origin.

2. Metastatic growths.

3. Cysts.

In spite of this attempt to gather all tumours under one scheme of classification, the general tendency is to treat the retinal and the choroidal groups separately. Thus Grinker (1932) divides the retinal tumours into :-

1. those arising from the primitive retinal or ciliary epithelium, medullo-epitheliomata;

2. those arising from the hypothetical bipotential retinoblast, retinoblastomata;

3. and those having their origin in primitive spongioblasts or neuro-epithelium, neuro-epitheliomata.

Tumours of the choroid have been classified by Callender (1931) into 4 main groups, all of which are considered melanotic tumours.

1. Spindle cell type $(a)$ heavily pigmented,

(b) slightly pigmented; prominent nucleolus.

2. Epithelioid type-pigment variable.

3. Fascicular type-pigment scanty; cells in columns and fasciculi.

4. Mixed type-heavily pigmented; commonest.

These classifications do not take into consideration several important points, the chief of which are :-

(1) that retinal tumours, because of their neural origin, should be classified on a basis similar to that adopted for the glial tumours of the central nervous system, and (2) that choroidal tumours need not invariably be of the melanotic type. 


\section{Neural Cell Development}

Tumours of the retina and the optic nerve arise from the neural elements of those structures or from their blood vessels. As tumours of neural origin are by far the commoner it will be of advantage to consider in a general way the development of the eye. In embryonic development the retina and the optic nerve originate from an evagination of the primitive optic vesicle which is made up of primitive medullary epithelium of the type found in the neural tube. Progressive development of these cells eventually gives rise to the neural elements of the adult retina. The various stages are shown in the following diagram given by Grinker (1932).

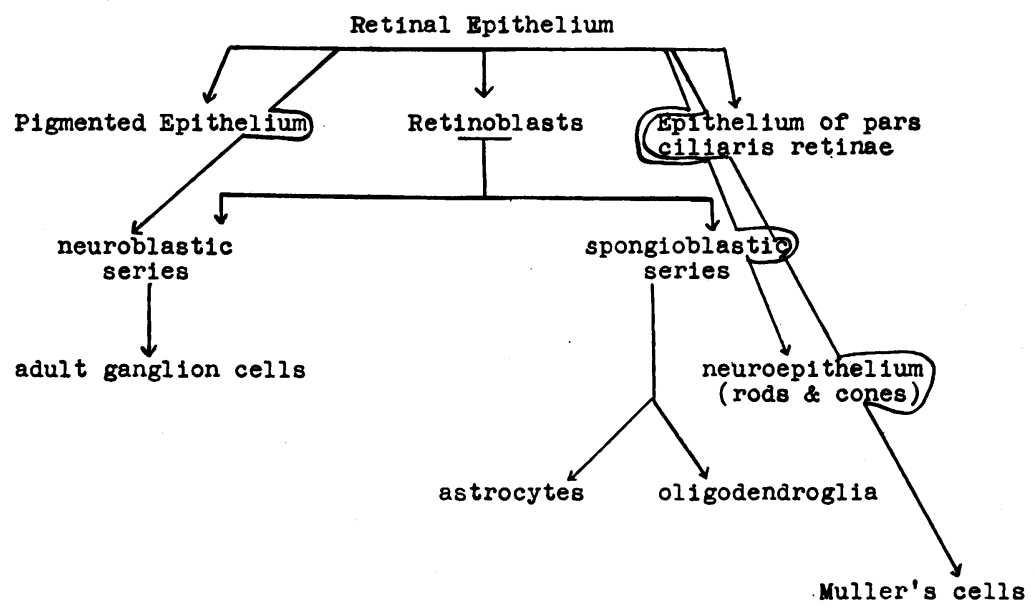

FIG. 1.

As the retinoblast is considered to be practically identical with the medulloblast of the central nervous system, it becomes evident that all the types of cells utilised in the classification of the neural tumours of the central nervous system are present in the development of the retina. This emphasises the possibility of an analogous classification for tumours of the retina.

In practice, it is as a rule impossible to classify the tumour cells on as detailed a basis as shown in Fig. 1. For the purpose of constructing a workable classification a more simplified scheme of development will be useful.

Broadly considered cells of neural origin pass from the neuroepithelial to the spongioblastic stage; the latter can be divided into (1) a primitive or apolar spongioblastic and (2) a polar spongioblastic group. From this point the more advanced specialisation becomes evident, and in the case of the elements 
other than the glia the next phase is the neuroblastic which is followed by the neurocytic phase. In a corresponding way the glia would at these stages go through both the "blast" and the "cyte" stages. The abbreviated scheme of development is graphically represented in Fig. 2.

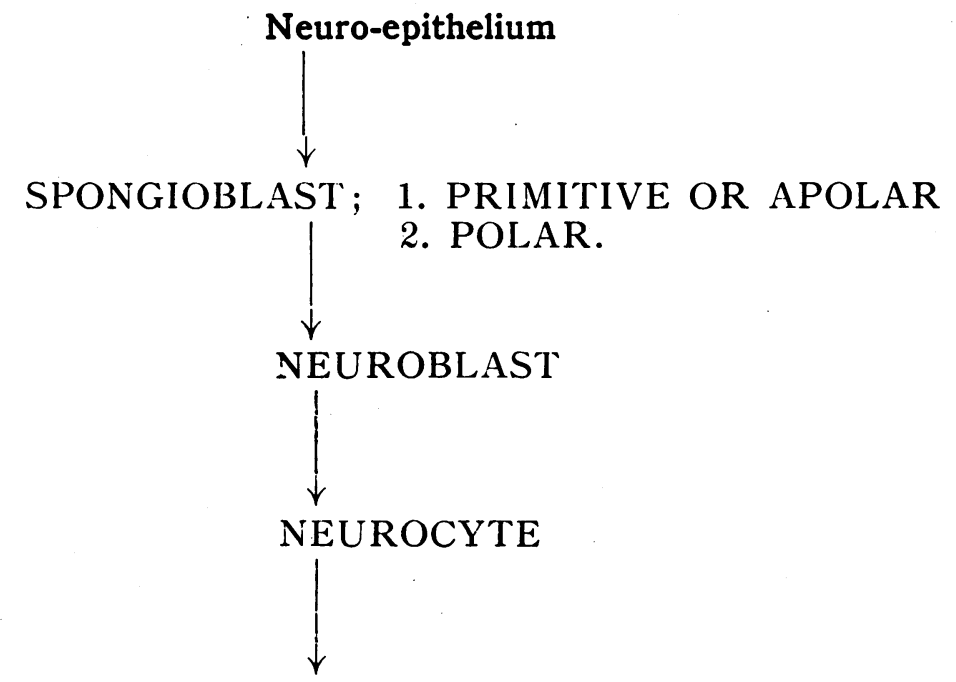

FIG. 2.

\section{Classification of Tumours of the Retina}

In any classification simplicity and elasticity are important. In order to achieve this only the most outstanding features of the tumours were utilised in constructing the classification. On this basis only 3 major types were necessary, namely, the neural tumours, the sarcomata and the melanomata of the choroid.

The neural tumours were divided into the following groups on the developmental basis, and from the less differentiated to the more differentiated types.

(a) Neuro-epitheliomata.-This group includes the medulloepitheliomata and the neuro-epitheliomata of Grinker's classification. The tumours of this group may be composed essentially of columnar epithelium (Fig. 3) resembling primitive medullary and retinal epithelium, and showing evidence of differentiation into retinoblasts, neuro-epithelium with rosette formation (Fig. 4), spongioblasts, ependymal cells (Fig. 5), and even adult glia. In some tumours there are features of the embryonic retina. Mitotic figures may be quite numerous. 


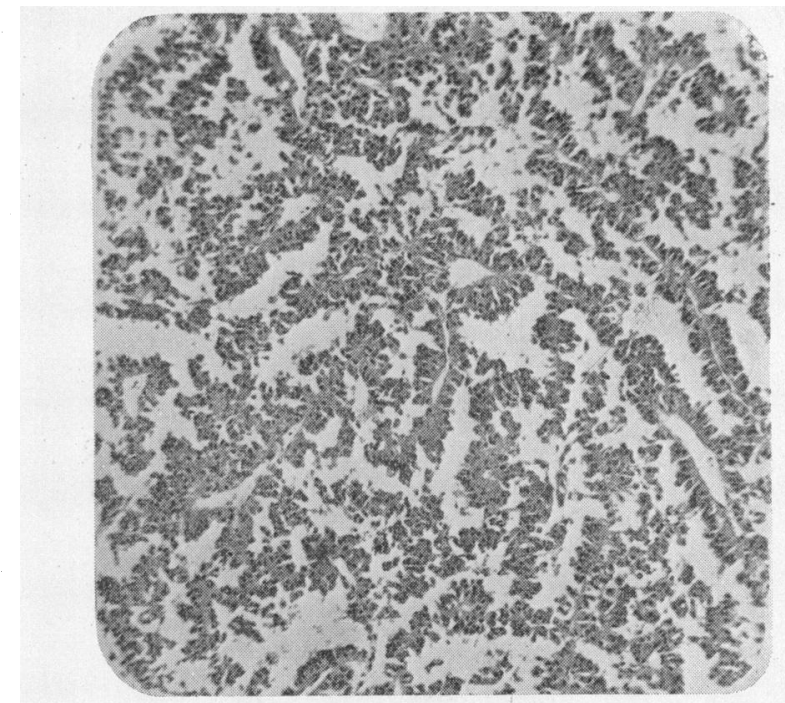

FIG. 3

Neuro-epithelioma of the Retina. There are numerous spaces lined by columnar cells of the type seen in early developing nervous tissue. The stroma is very scanty. $\times 80$.

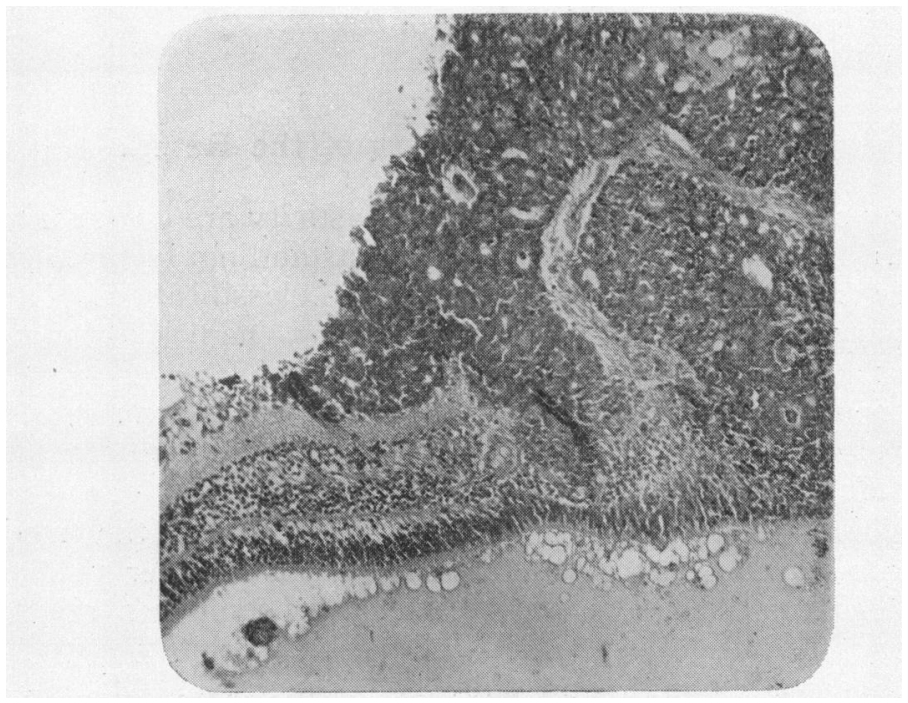

FIG. 4.

Neuro-epithelioma of the Retina. This shows continuity between the tumour and the retina. Rosettes are numerous. Such tumours have been referred to as adenomata. $\times 80$. 


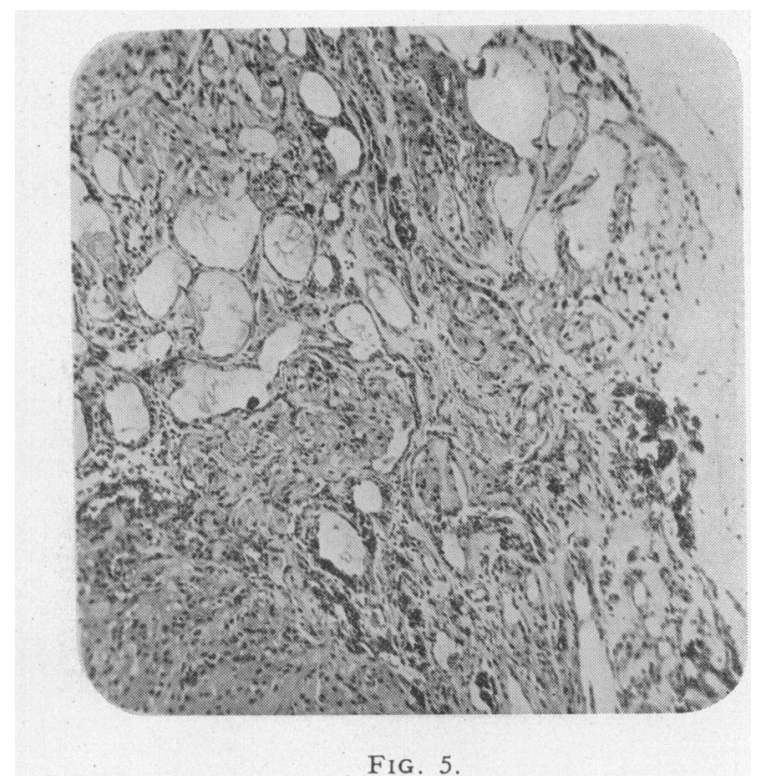

Neuro-epithelioma of the Iris. The numerous spaces are lined by flattened ependymal cells. $\times 80$.

Many tumours of this group are made up of rather large spheroidal and polyhedral cells of the type seen in the so-called neurogenic sarcomata of the peripheral nerves. The cells as a rule have an eosinophilic cytoplasm and a distinct and well stained nucleus. This type is probably very undifferentiated and even more so than those of the previous types.

(b) Spongioblastic Group.-1. Apolar or Primitive Spongioblastomata.- The tumour classed under this heading is generally termed a retinoblastoma, and it is very similar to the medulloblastoma of the central nervous system. According to Penfield the medulloblast is an apolar spongioblast and as the medulloblast and the retinoblast are identical, the retinoblast can also be considered an apolar spongioblast. Hence in order to retain continuity in the classification the retinoblastoma may be termed an apolar or primitive spongioblastoma.

The growth is made up of small or polyhedral cells, some of which will show tapering at one end; the cells as a whole have scanty cytoplasm. They are closely packed with large, darkly staining nuclei (Figs. 6 and 7). Mitotic figures are numerous. The tumour may also contain pseudo-rosettes, polar spongioblasts, astroblasts, and astrocytes.

The tumour usually originates in the posterior part of the retina and even from the papilla. It may infiltrate and produce metastases. 


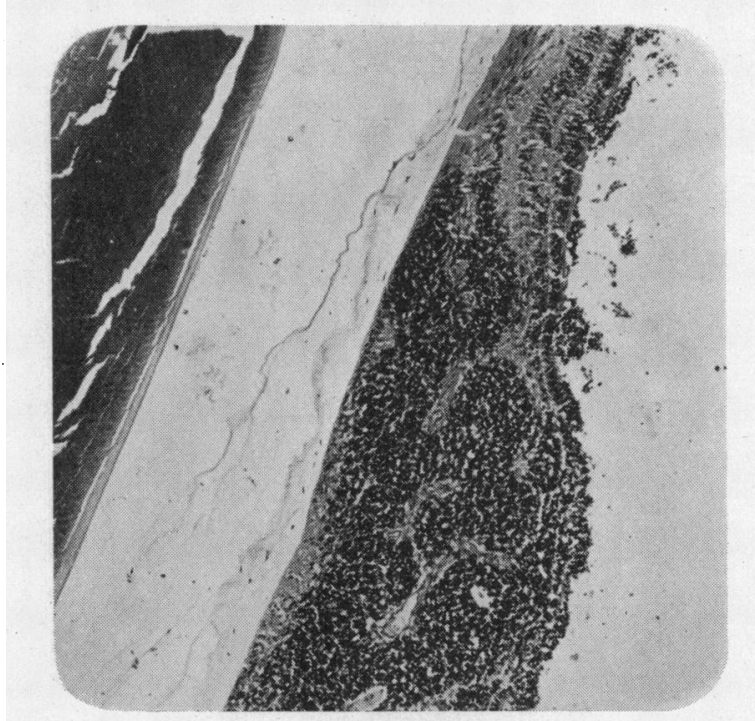

Fig. 6.

Apolar Spongioblastoma or Retinoblastoma of the Retina. Its relationship with the retina is distinctly seen. The tumour is made up of small closely packed cells with darkly staining nuclei. $\times 50$.

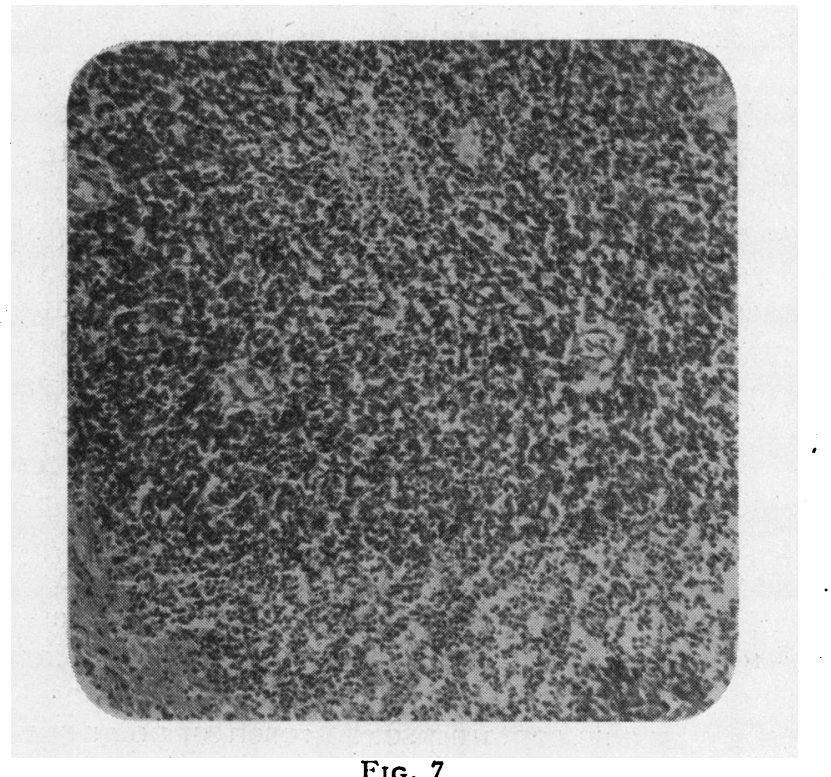

Fig. 7

Apolar Spongioblastoma or Retinoblastoma of the Retina. A highpower view of the same tumour to show the closely packed small cells with occasional tapered cells amongst them. $\times 125$. 
2. Polar Spongioblastomata.-As in the central nervous system, the gross histological features of the polar spongioblastoma suggest a close similarity with the spindle cell sarcoma of other tissues. If a tumour of the eye gives the impression, histologically, of a spindle cell sarcoma, spongioblastoma polare must be eliminated first.

The tumour is made up uniformly of fairly large fusiform cells (Fig. 8) with a cytoplasmic process from one or both ends. These processes are not connected with the connective tissue septa, nor

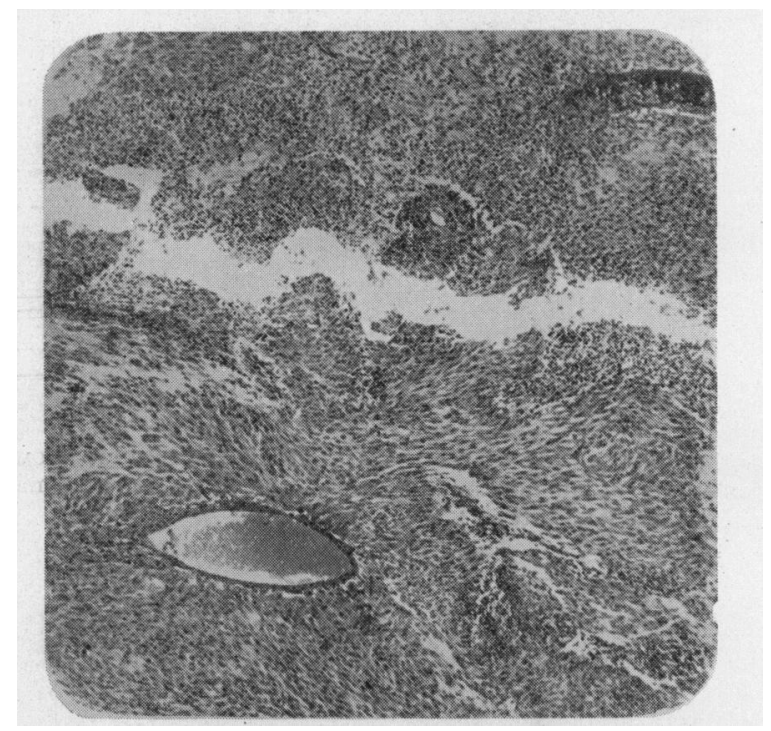

FIG. 8.

Polar Spongioblastoma. Fusiform cells are abundant and typical of this type of neoplasm. $\times 50$.

attached to the blood vessels, and they do not stain specifically with Mallory's phosphotungstic acid stain. In places the cells tend to be parallel and at times closely resemble the central neurinoma. As a rule, the blood vessels of the tumour are well formed. As the tumour is slowly growing, mitotic figures are rare and necrosis is not common.

These neoplasms are generally included in the melanoma group.

(c) Neuroblastic Group.-Tumours composed of neuroblasts or reurocytes can be distinguished both by the advanced degree of differentiation evident in the tumour, in the form of attempts to develop recognisable retinal structures (Figs. 9 and 10), and also by the presence of a deeply staining nucleolus in a well-defined 


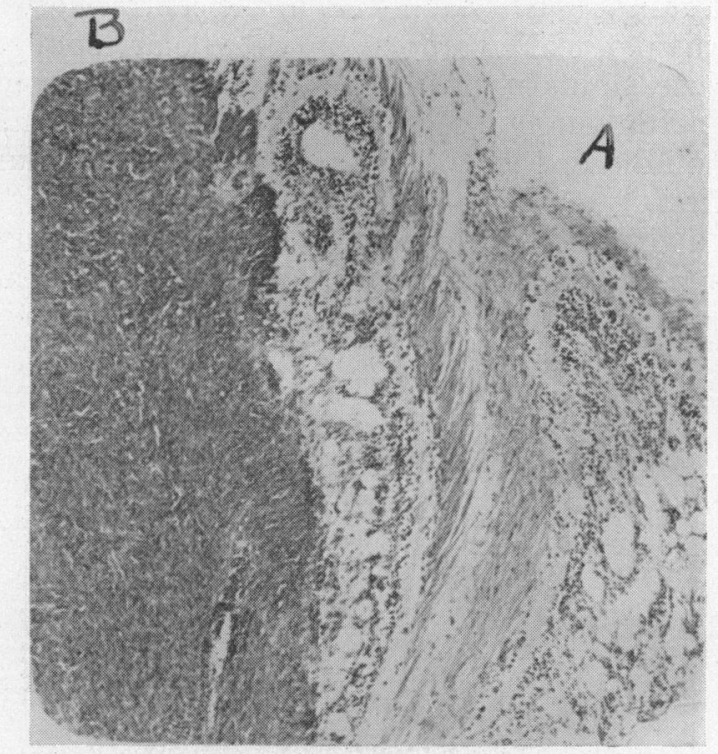

FIG. 9.

Neuroblastoma of the Retina. One. half of the tumour shows retinal differentiation of an advanced type (A) but in the portion marked (B) neuroblasts predominate. $\times 50$.

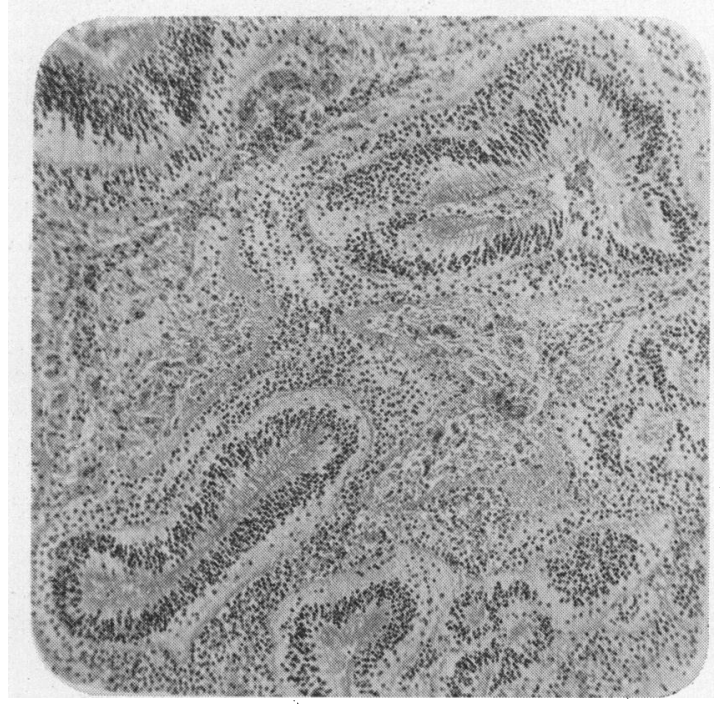

Fig. 10.

Neurocytoma of the Retina. The neoplastic process has resulted in forming recognisable retina with the formation of layers or zones as seen in the retina. $\times 80$. 
nucleus. The predominance in the growth either of neurocytes or neuroblasts, as the case may be, determines whether the tumour is to be classed as a neurocytoma or a neuroblastorna.

Although only the pure types have been described throughout, the fact remains that mixed and intermediate types are very

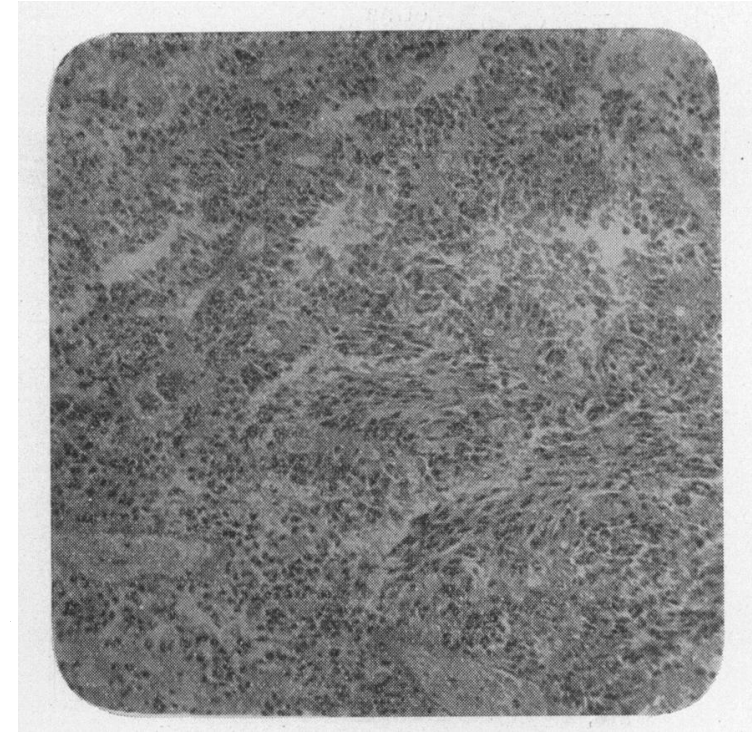

FIG. 11 .

Polar Spongioblastoma showing Neuro-epithelial Elements. $\quad \times 125$.

common, as for example in Fig. 11 where polar spongioblasts are common but neuro-epithlial features are also present. These mixed types have formed connecting links between all the groups described in the above classification.

\section{Results-Retinal Tumours}

In the following table the retinal tumours are grouped on the basis explained above, and along with this are given details relevant to this investigation.

Classification of Tumours of the Choroid.-Tumours of the choroid have their own special features and these must be considered in dealing with the classification of tumours of this region. In addition, the structural peculiarities of the choroid itself must be taken into consideration. Since the choroid forms the outer sheath to the retina, some tumours arising in that region might show some similarity with the perineural fibroblastomata. 
TABLE I

Retinal Tumours Classified on a Developmental Basis. NEURO-EPITHELIOMA

\begin{tabular}{|c|c|c|c|c|}
\hline No. & Sex and Age & Site & Pigment & $\begin{array}{l}\text { Benign or } \\
\text { Malignant }\end{array}$ \\
\hline $28-115$ & - & Retina & $4+$ & M. \\
\hline $28-346$ & Male, $6 / 12$ & Retina & $1+$ & M. \\
\hline $33-172$ & Male, 39 & Iris & $2+$ & M. \\
\hline $29-400$ & Male & Retina & - & M. \\
\hline $31-455$ & Male & Retina & $1+$ & M. \\
\hline $34-248$ & Male & Retina & - & M. \\
\hline $35-226^{-}$ & Male, 59 & Retina & $2+$ & M. \\
\hline \multicolumn{5}{|c|}{ POLAR (PRIMITIVE) SPONGIOBLASTOMA } \\
\hline $28-161$ & Male & Retina & $4+$ & M. \\
\hline $25-385$ & Female & Retina & $1+$ & M. \\
\hline $28-288$ & - & Retina & $1+$ & M. \\
\hline $25-732$ & Male & Retina & $1+$ & M. \\
\hline $28-381$ & Male, 3 & Retina & \pm & M. \\
\hline $27-118$ & - & Retina & 二 & M. \\
\hline $27-323$ & Male & Retina & - & M. \\
\hline $28-344$ & Male, 3 & Retina & - & M. \\
\hline $34-91$ & Male, 2 & Retina & $1+$ & M. \\
\hline $34-144$ & Female, 7 & Retina & - & M. \\
\hline $34-335$ & Male, 2 & Retina & - & M. \\
\hline $36-180$ & Female & Retina & - & M. \\
\hline $37-209$ & Male, 4 & Retina & - & M. \\
\hline \multicolumn{5}{|c|}{ olar Spongioblastoma } \\
\hline $27-232$ & Male, 45 & Retina & $1+$ & \multirow{13}{*}{ ? B. } \\
\hline $28-348$ & - & Retina & $1+$ & \\
\hline $31-144$ & Female & Choroid & $1+$ & \\
\hline $31-230$ & Male & Choroid & \pm & \\
\hline $33-650$ & Male & Choroid & $\overline{4+}$ & \\
\hline $34-357$ & Male, 36 & Retina & - & \\
\hline $34-474$ & Male & Retina & $1+$ & \\
\hline $35-69$ & Male & Choroid & $3+$ & \\
\hline $35-418$ & Female & Retina & $1+$ & \\
\hline $36-246$ & Female, 49 & Choroid & $2+$ & \\
\hline $37-118$ & Male, 79 & Ciliary body & $1+$ & \\
\hline $37-397$ & Male, 37 & Retina & $4+$ & \\
\hline $37-410$ & Female, 44 & Choroid & $4+$ & \\
\hline \multicolumn{5}{|c|}{ EUROBLASTOMA } \\
\hline $31-260$ & Male & Retina & $1+$ & M. \\
\hline $34-293$ & Female & Retina & - & M. \\
\hline $35-576$ & Male, 64 & Retina & $1+$ & M. \\
\hline \multicolumn{5}{|c|}{ NEUROCYTOMA } \\
\hline $32-52$ & Male, 8 & Retina & $1+$ & M. \\
\hline $33-681$ & Male, 3 & Retina & - & B. \\
\hline
\end{tabular}


Furthermore, the particular differentiation of the choroid itself gives rise to neoplastic features of a distinctive type other than the presence of melanin, for melanin alone is of doubtful value as a basic feature for the classification of tumours of the choroid. Since a great variety of disturbances of the choroid will give rise to an increased production of choroidal pigment, the presence or absence of pigment in the tumour takes on a secondary significance. Hence the presence of pigment in an intra-ocular tumour

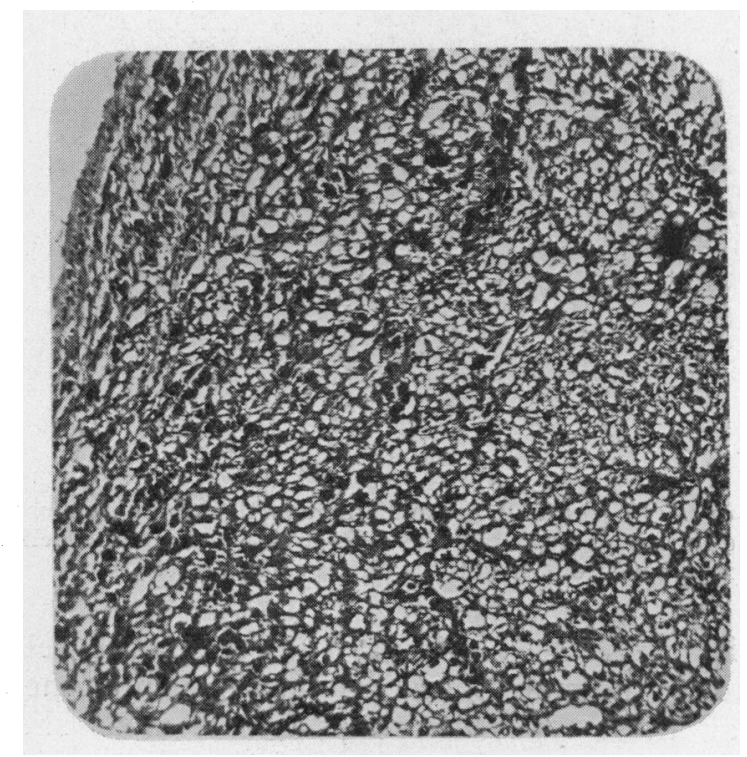

FIG. 12.

Sarcoma of the Choroid. This shows the differentiation of the choroidal tumour into the cavernous form. The stroma is made up of small fusiform cells as seen in the choroid. $\times 80$.

does not imply that the tumour is primarily one of the choroid; neither can it be inferred on this ground alone that the tumour is of melanotic origin. The presence of melanotic pigment in a tumour merely implies that the growth has disturbed the choroid. The classification of choroidal tumours can be based with more certainty on cell differentiation rather than on the presence or absence of pigment. If the tumour is of choroidal origin the cellular differentiation should tend towards the choroidal structure, and in its more advanced form it should tend to show the cavernous appearance of the choroid (Fig. 12). In their malignant forms these tumours are sarcomata.

The malignant tumours of the choroid can be divided into 3 


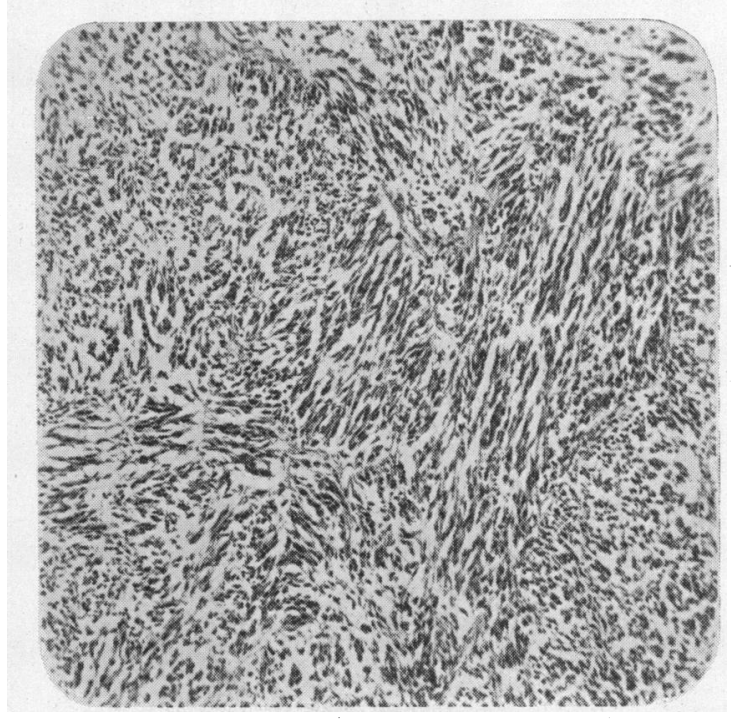

FIG. 13.

Sarcoma of the Choroid. In the malignant portion of the tumour which is included in this photograph, the cells are of the spindle cell type. In other parts cavernous structures were evident. $\times 80$.

types: (a) the round cell sarcoma, (b) the spindle cell sarcoma (Fig. 13), and (c) the more specialised types such as the myxosarcoma. In all these types there are as rule areas showing the fenestrated or cavernous appearance of the choroid. In other words the tumours are essentially malignant choroidomata.

(1) Sarcomata.

\section{Results-Tumours of the Choroid}

TABLE II

Sarcomata of the Choroid divided into Groups according to Cell Types.

Round Cell Type

\begin{tabular}{l|l|c|c|c}
\hline \multicolumn{1}{c|}{ No. } & Sex and Age & Site & Pigment & $\begin{array}{c}\text { Benign or } \\
\text { Malignant }\end{array}$ \\
\hline $28-93$ & Female & Choroid & + & M. \\
$34-8$ & Male & Choroid & $\frac{+}{1+}$ & M. \\
$35-443$ & Male & Choroid & $1+$ & M.
\end{tabular}


Spindle Celi Type

TABLE II-continued

\begin{tabular}{l|l|l|c|c}
\hline No. & Sex and Age & Site & Pigment & $\begin{array}{c}\text { Benign or } \\
\text { Malignant }\end{array}$ \\
\hline $27-200$ & Male, 52 & Choroid & $3+$ & M. \\
$28-83$ & Male, 60 & Choroid & $2+$ & M. \\
$35-54$ & Female, 70 & Choroid & $1+$ & M. \\
$33-48$ & Male & Choroid & $3+$ & M. \\
$33-285$ & Female, 37 & Choroid & $4+$ & M. \\
$33-686$ & Female, 51 & Choroid & $5+$ & M. \\
$34-21$ & Male, 35 & Choroid & $1+$ & M. \\
34-181 & Male, 58 & Choroid & $1+$ & M. \\
$34-405$ & Female & Choroid & $3+$ & M. \\
$34-476$ & Female, 63 & Choroid & $4+$ & M. \\
$36-129$ & Female & Choroid & $1+$ & M. \\
37-167 & Male, 55 & Choroid & $3+$ & M. \\
37-261 & Male & Ciliary body & $2+$ & M. \\
37-470 & Male, 37 & Choroid & $2+$ & M. \\
32-564 & Male & Choroid & $1+$ & M. \\
& & & & myxosarcoma \\
\hline
\end{tabular}

(2) Melanomata.-The remaining group is made up of the melanomata. These are tumours of the choroid and are highly pigmented as a rule. The tumour cells are of the large triangular or branching type; in parts they may be of the fusiform, rounded or polyhedral types. As the presence of melanotic pigment alone is an inadequate criterion, the fundamental feature of this group is the presence of the branching melanotic cells even though these may form a small part of the tumour.

TABLE III

Melanomata of Choroid.

\begin{tabular}{c|l|l|c|c}
\hline No. & Sex and Age & Site & Pigment & $\begin{array}{c}\text { Benign or } \\
\text { Malignant }\end{array}$ \\
\hline $28-134$ & Male & Choroid & $4+$ & M. \\
$32-247$ & Male & Choroid & $2+$ & M. \\
$37-168$ & Male, 67 & Choroid & $5+$ & M. \\
$37-197$ & Male, 60 & Choroid & $5+$ & M. \\
\hline
\end{tabular}

\section{Discussion}

The findings are limited because clinical correlation could not be established. Information as to age was lacking in many cases, and this further limited the scope of this investigation. In spite of these deficiences the histological features of the tumours are 
sufficiently distinct, and their histogenesis sufficiently clear to permit them to be divided into a number of groups according to the main constituent cell type of the tumour.

The classification of tumours of the retina hardly requires any further discussion. The present scheme has a developmental basis and the criteria for each group are sufficiently general to allow as much latitude as is the case in the classification of the glial tumours of the central nervous system. These points have already been dealt with in some detail.

Of the neural tumours 7 fell into the neuro-epithelial group and all of these were malignant. Only 1 appeared to originate in the iris. Two out of the 7 were devoid of ptgment, while the remainder contained varying amounts of melanin. The apolar spongioblastoma or retinoblastoma group was made up of 12 cases and these, too, were all maiignant. The age was available in 5 cases only; 4 were either 2 or 3 years of age and 1 was 7 years of age. All except one contained little or no pigment. The polar spongioblastomata (11 cases) originated in the retina in 6 and in the choroid in 5 cases. These latter tumours appear to occur only in adults, according to the limited information available; all except 2 contained an appreciable amount of pigment. As both nuclear variations and invasions were absent these tumours were presumed to be benign.

The criteria for the choroidal tumours are on a different basis. The choroid forms the outer covering of the retina, a neural structure, and it might be expected that it would give rise to tumours similar to the perineural fibroblastoma or neurofibroma, but no tumours of this type were found in the present series; the majority, however, showed a specific differentiation into choroidal structures.

Besides the melanomata the tumours of the choroid are essentially of 2 groups and these are here classified either as polar spongioblastomata or as sarcomata. Neither show the characteristics of the perineural fibroblastoma or neurofibroma. The spongioblastoma of the choroid not uncommonly shows palisading of the fusiform cells very similar to that seen in the perineural fibroblastoma; in the spongioblastoma, however, there is no relationship between the neoplastic tissue and any form of connective tissue. In direct contrast these choroidal tumours invariably show neuro-epithelial features. If these tumours are entirely within the choroid the question arises as to how they could be neuro-epithelial rather than connective tissue in origin. There is the possibility that the sectioned tissue does not represent the part where the choroidal and the retinal neoplastic tissue are continuous. In other words, it is just possible that here we are dealing with tumours of the retina and that the section merely 
shows tissue that had invaded the choroid. The other possibility is that these tumours have arisen from embryonic rests.

The sarcomata of the choroid are instructive in that there is in these tumours a definite attempt to reproduce the hemangiomatous appearance of the choroid, a point that suggests that these tumours are specific tumours of the choroid and not sarcomata of the general type. According to this view, these tumours of the choroid may be classed as the less differentiated (round cell), and the more differentiated (spindle cell) types of malignant tumours of the choroid; the degree of malignancy would probably vary accordingly. In the past the more obvious tumours of this type in which there has been choroid differentiation, have been classed as haemangiomata or as haemangio-endotheliomata of the choroid, either benign or malignant as the case may be. The majority, however, have been considered as malignant melanomata, and largely because they contain pigment.

\section{TABLE IV}

Comparison of the Amount of Pigment Present in the Various Types of Tumours

TUMOURS OF THE RETINA

\begin{tabular}{|c|c|c|c|c|c|c|c|c|c|c|}
\hline \multirow{2}{*}{\multicolumn{2}{|c|}{ Type of Tumour }} & & \multirow{2}{*}{$\begin{array}{l}\text { No. of } \\
\text { cases }\end{array}$} & \multicolumn{7}{|c|}{ A mount of Pigment } \\
\hline & & & & 0 & $\doteqdot$ & $1+$ & $2+$ & $3+$ & $4+$ & $5+$ \\
\hline Neurocytoma & - & - & 2 & 1 & 0 & 1 & 0 & 0 & 0 & 0 \\
\hline Neuroblastoma - & - & - & 3 & 1 & 0 & 2 & 0 & 0 & 0 & 0 \\
\hline Polar Spongioblast & ma & - & 7 & 1 & 1 & 4 & 0 & 0 & 1 & 0 \\
\hline $\begin{array}{l}\text { Apolar Spongiobla } \\
\text { (retinoblastom }\end{array}$ & toma & & 13 & 7 & 1 & 4 & 0 & 0 & 1 & 0 \\
\hline Neuroepithelioma & - & - & 7 & 2 & 0 & 2 & 2 & 0 & 1 & 0 \\
\hline Total - & - & - & 32 & 12 & 2 & 13 & 2 & 0 & 3 & 0 \\
\hline
\end{tabular}

Tumours OF THE CHOROID

\begin{tabular}{rr|r|r|r|r|r|r|r|r}
\hline $\begin{array}{l}\text { Polar spongioblastoma } \\
\text { Sarcoma }\end{array}$ & 6 & 0 & 0 & 2 & 1 & 1 & 2 & 0 \\
(1) spindle cell - & - & 13 & 0 & 0 & 4 & 2 & 4 & 2 & 1 \\
(2) round cell - & - & 3 & 0 & 1 & 2 & 0 & 0 & 0 & 0 \\
(3) myxo - - & - & 1 & 0 & 0 & 1 & 0 & 0 & 0 & 0 \\
Melanoma - - & - & 4 & 0 & 0 & 0 & 1 & 0 & 1 & 2 \\
\hline Totai - - - & 27 & 0 & 1 & 9 & 4 & 5 & 5 & 3 \\
Sarcoma ciliary body & - & 1 & 0 & 0 & 0 & 1 & 0 & 0 & 0 \\
\hline
\end{tabular}


To what extent is the melanotic pigment of significance? Table IV shows that the melanotic pigment was definitely present in 20 of the retinal tumours out of a total of 32 in all. Amongst the choroidal tumours, however, none was without pigment and all but 1 showed more than a trace. In inflammatory disease of the eye it is generally accepted that any disturbance of the choroid is likely to give rise to increased melanin production in the disturbed part. The result of the analysis of Table IV shows that only 5 retinal tumours out of a total of 32 had $2+$ or more of pigment, while amongst the choroidal tumours only 10 showed readings below that amount. The following is a more detailed analysis. While none of the choroidal tumours was without pigment yet the retinal group of tumours had 37.5 per cent. that fell into this group. A moderate amount of pigment $(2+)$ or less was present in 84.4 per cent. of the retinal tumours and in 37.1 per cent. of the choroidal tumours. More than a moderate amount $(2+)$ was found in 15.6 per cent. of the retinal tumours and in 62.9 per cent. of those originating in the choroid. This would confirm the opinion already stated that melanotic pigment in itself is not sufficient for the diagnosis of melanoma. It suggests that the choroid has been disturbed ; it is present in retinal tumours, but the larger amounts are more likely to be found in the choroidal tumours.

\section{Summary and Conclusions}

1. Intra-ocular tumours are essentially of three types:

(a) Retinal tumours of neural origin.

(b) Sarcomata of the choroid showing choroidal differentiation.

(c) Melanomata of the choroid.

2. Retinal tumours can be classified on a developmental basis analogous to the classification of Bailey and Cushing for glial tumours of the central nervous system. Accordingly, they can be divided into, neuro-epitheliomata, apolar spongioblastomata, polar spongioblastomata, neuro-blastomata, and neuro-cytomata.

3. Sarcomata of the choroid although they can be divided morphologically into the round cell and spindle cell types, and an occasional tumour of the mixed group, e.g., myxo-sarcoma, usually show differentiation into recognisable choroidal structures in parts. Hence they should be considered as malignant choroidomata.

4. Melanomata are comparatively few and contain the typical branched melanotic cells.

5. Pigment may be present in many retinal tumours and is therefore not diagnostic of a melanoma. 
To Professor S. L. Baker I am grateful for his interest and helpful criticism. I am indebted to Mr. H. C. Taylor of the Department of Pathology, Manchester University, for the photomicrographs.

\section{REPERENCES}

Callender, G. R.-Trans. Amer. Acad. Ophthal., Vol. XXXVI, p. 131-142, 1931.

Collins, E. T. and MaYou, M. S. - Pathology and Bacteriology of Eye. Philadelphia: P. Blackistons Son \& Co. 1925.

GRINKER, R. R.-Cytology and Cellular Pathology of the Nervous System. Edited by W. Penfield. Vol. III. Section Tumours of Retina (p. 1043.) Paul B. Hoeber, Inc. New York. 1932.

\section{RADON TREATMENT OF SECONDARY CARCINOMA OF THE CHOROID.* Post-Mortem Observations}

BY

\section{P. JaMESON Evans BIRMINGHAM}

IN September, 1937, I reported the use of radon seeds in the treatment of secondary carcinoma of the choroid in a woman 41 years old. The report described the appearance of growth in the sole remaining eye during March, 1936, the other having been removed for the same condition in January, 1936, and its treatment by radon with disappearance of growth for a period of seven months, and the similar treatment of a further metastasis in the same eye in October, 1936.

The subsequent history is of some interest and is briefly stated thus :-

January, 1937. Vision was 6/12 (i) and there was no evidence of the presence of choroidal growth. A severe reaction of the choroid, similar to that already present in the lower half of the eye, appeared and continued. The retina remained flat but, with the passing of time, became infiltrated with choroidal pigment derived from the stippled pigment in the affected area. The whole macular region was involved and it was surprising how central visual acuity could be maintained. However, the patient continued to maintain vision of $6 / 12$ and could thread her own needles with suitable glasses.

In March, 1937, the patient had severe attacks of vomiting,

* Use of Radon in the Treatment of Metastatic Carcinoma of the Choroid. Brit. Jl. of Ophthal., p. 496, September, 1937. 